\title{
Energy Recovery from Biomass: Process Simulation and Second Law Analysis of an Anaerobic Digester Coupled with an Internal Combustion Engine
}

\author{
Luigi Sallustio*,1 $^{*}$ Enrico Sciubba* \\ *Department of Mechanical and Aeronautical Engineering \\ University of Roma $1 \mathrm{La}$ Sapienza \\ E-mail: ${ }^{1}$ luigi.sallustio@gmail.com
}

\begin{abstract}
The paper presents the simulation and the exergy analysis of a power generation system fuelled by the organic fraction of solid urban refuse and food farming waste: biogas is generated in an anaerobic digester (AD) and then burnt in an internal combustion engine (ICE). Proper thermodynamic models of both components have been developed and implemented into the library of a modular object-oriented Process Simulator, CAMEL-Pro ${ }^{\circledR}$. Mass-, energy- and exergy balances are performed not only for the whole plant but also at a more disaggregated level, to properly allocate the thermodynamic inefficiencies to each component; for the AD an additional distinction is made as to the allocation of the outputs, because the digested substrate may in fact be accounted for either as a plant waste flow or as a plant product. The results show a good agreement with the available experimental data, so that the model presented here may be considered as having being validated in terms of mass of biogas per year and net electrical and thermal power output. Quite surprisingly, a second law analysis reveals a very high exergy efficiency of the anaerobic digester, in the range of $91 \%$. Some discussion of this point is also presented.
\end{abstract}

Keywords: Anaerobic digester; biomass energy recovery; biogasification.

\section{Introduction}

The simultaneous constraints posed by the ever increasing energy demand of urban communities and the similarly increasing production of municipal solid waste (MSW) has led Engineers and Energy Planners to consider disposing of MSW in waste-to-energy plants in which the refuse, properly separated, dried and pre-treated, is burnt or gasified to generate steam and/or electricity. For a substantial fraction of MSW there is though an alternative conversion process, namely the anaerobic digestion of the organic fraction: this is regarded as a "greener" option, generates a considerable amount of biogas per ton, and enjoys the additional advantage of producing significantly smaller volumes of final by-products, a non negligible portion of which may be further reprocessed into a fertilizer.

In this paper, we examine an anaerobic digestion unit coupled with an internal combustion engine, to evaluate its energy conversion efficiency, its dependence on scale effects (tons/year of available biomass), and its exergy efficiency.

An object-oriented Process Simulator (CAMEL-Pro, developed by the Authors' group at the University of Roma Sapienza) has been used to simulate the Biomass-to-Energy process: to this goal, two new components were added to its library, namely an anaerobic digester (AD) and an internal combustion engine (ICE).

Several models of $\mathrm{AD}$ are reported in the current literature, such as in Batstone et al. (2002) and Sötemann et al. (2005), but most of them are specialized for a specific process chain or for a certain feedstock. The AD model presented in this work has been constructed instead so as to simulate any type of process with a wide variety of feedstocks, because the composition of the feed stream at reactor inlet is specified in terms of its weight content in water, organic matter and volatile organic matter rather than in its chemical composition. In fact, the two models presented in this work are designed to investigate the production potential of the digestion process, and therefore use simplified sets of equations that do not include a detailed model of all of the chemical and biochemical reactions that take place in the real components.

A peculiarity of CAMEL-Pro is the possibility of performing an exergy analysis of the process without having to recur to post-processing of the data: thus, a Second Law analysis of the plant is one of the "natural" outputs of the simulation. Here, this feature has been exploited to calculate the exergy-based performance of the biomass-to-energy process.

\section{Process Description}

The process simulated in this study is representative of the typical plant layout of an anaerobic digester coupled with an internal combustion engine (Archea, 2009; Kompogas AG, 2009; ONR, 2008; Rota Guido srl, 2009). Scope of this work is to evaluate the amount of energy that can recovered by the system and to perform an exergy efficiency analysis of the two coupled units: therefore, all engineering parameters strictly peculiar of a specific plant layout, such as the electrical consumption of the conveyor belts or the storage/backup system for the feedstock, have been neglected.

The layout of the plant considered in this study is represented by the block diagram shown in Figure 1 where the arrows represent the streams in and out of components (only fuels and products are represented): a significant simplification with respect to an industrial P\&I diagram is apparent (Zeb et. al., 2013). For example, the water 
distributor is represented as a flow splitter that performs two functions: to provide the water at a certain temperature to the $\mathrm{AD}$ and to direct the remaining amount to the thermal user; a single flow mixer is inserted in the diagram to collect all the cold water streams and send them back to the cogenerated ICE, and so on. The thermal user simply represents a "sink" for the net thermal power produced by the plant. In real applications, the water distribution is slightly more complex: the user receives water at about 90$95^{\circ} \mathrm{C}$ while the digester requires substantially lower temperatures $\left(35-55^{\circ} \mathrm{C}\right.$, depending on the bacterial strain): here, the losses on the user's side have been not included in the balance.

In Figure 1 the digested substrate (DS) is represented as a product, but in this study the system efficiency has been evaluated under two distinct assumptions: in the first, the DS is considered as a discharge and in the other one as a plant co-product. These two cases are representative of two real operating conditions in which the DS, a sort of compost, may be discharged to a landfill or sold as a N-rich fertilizer.

\section{Simulator Overview}

To perform the simulations described in this work, models of the AD and of the ICE have been implemented and integrated in an existing process simulator, CAMELPro ${ }^{\circledR}$, previously developed at the Authors' group at the University of Roma Sapienza. CAMEL (CIRCUS, 2013) is written in $\mathrm{C}++$ and $\mathrm{C \#}$, is based on a completely and genuine object-oriented approach, and is equipped with a user-friendly graphical interface that allows for the simulation and analysis of several energy conversion processes. The system is represented as a network of components connected by material and energy streams; each component is is an "object" characterized by a set of equations describing the thermodynamic changes imposed on the streams. In mathematical terms, this equation system is not closed, and therefore needs a proper number of boundary conditions in terms of known flow parameters. In practical terms, this means that the computed solution depends on both the plant configuration and on the assigned boundary conditions.

An optimized iterative Newton-Raphson algorithm is employed to solve the global equation system. One of the main features of CAMEL-Pro ${ }^{\circledR}$ is its modularity that enables users to expand the code by adding new components or by modifying the model of the existing ones: in fact we exploited these capabilities to introduce the proper process equations for the AD and for the ICE model. The real gas model adopted in CAMEL-Pro ${ }^{\circledR}$ prescribes that the specific heat be calculated by a fifth order polynomial in T (Lanzafame \& Messina, 2000). Enthalpy and entropy are then calculated by exact (i.e., analytical) integration of these polynomials. CAMEL-Pro ${ }^{\circledR}$ also includes the IAPWS library to calculate water/steam properties (The International Association for the Properties of Water and Steam, 1997) and contains a substantial database of thermophysical properties of a number of solids and liquids.

\subsection{The Digester \\ 3.1.1. Model Definition}

Anaerobic digester systems consist of a reactor, where the biogasification reaction takes place, and of auxiliary components whose arrangement strictly depends on the AD type, feedstock characteristics and plant layout.

For the purpose of this study, and to substantially simplify all considerations related to the plant layout, the $\mathrm{AD}$ has been represented as a semi-lumped component that includes:

1. The Reactor subsystem: This is the plenum in which all of the biochemical processes takes place. It consists of a cylindrical chamber maintained at a fixed temperature, determined by the type of active bacteria, in which the feedstock is inserted and extracted through two screw conveyors (not included in the present study). The reactor is also equipped with a mixer that provides the required mechanical mixing of the substrate to facilitate the reactions.

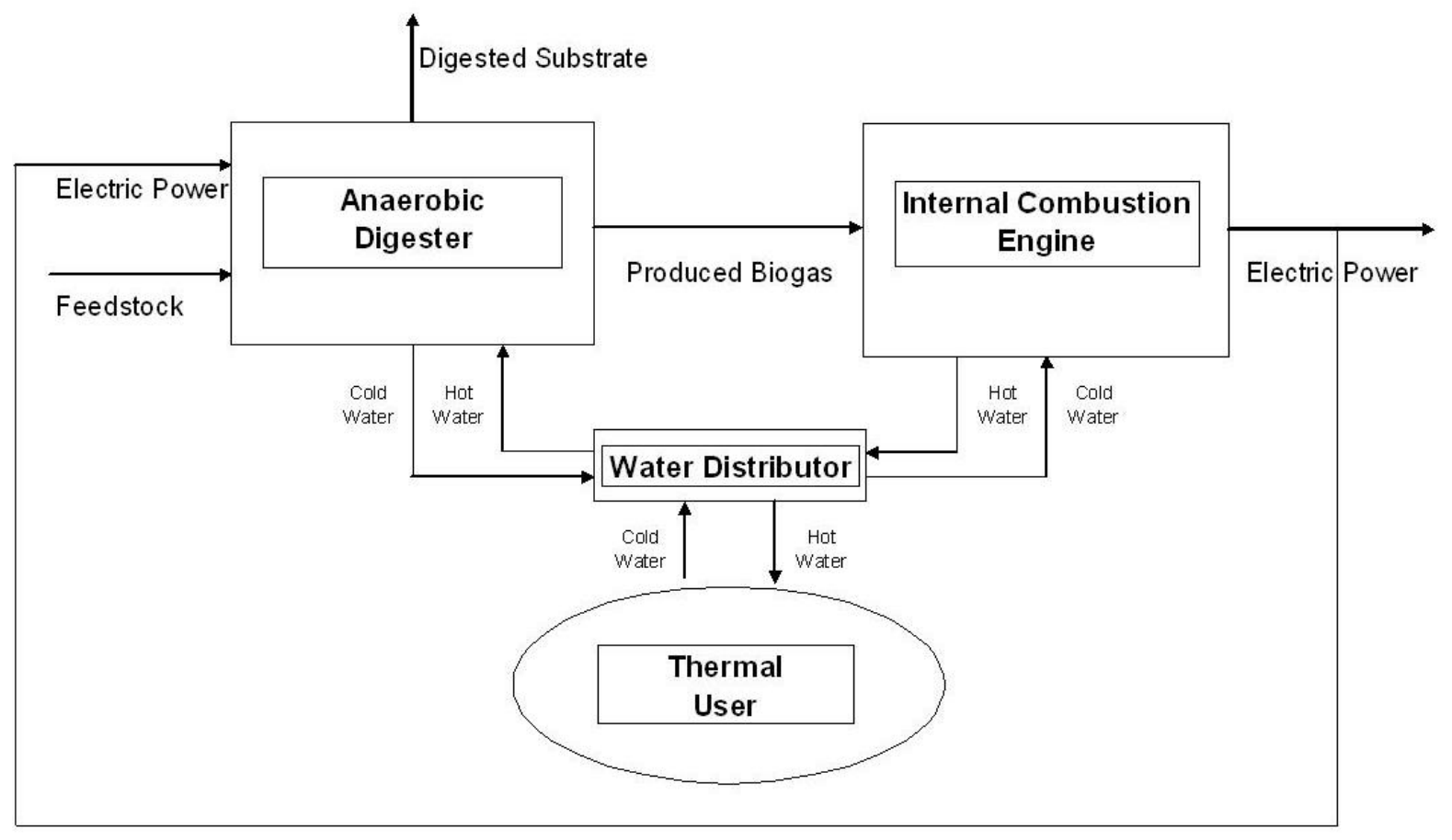

Figure 1. Block diagram of the plant. 
2. A Heat management subsystem: It manages the thermal flows throughout the system and monitors the reactor thermal level, using the mass flow rate of the heating water as a control variable.

3. The Electrical subsystem: It manages the only electrical component modeled in this study, the reactor's internal mixer mentioned in point 1 above.

The biochemical processes are lumped into a semiempirical model of digestion kinetics (Jewel et al., 1993; Richards et al., 1991; Richards et al., 1991; Richards et. al., 1994). The energy required by the mixer is accounted for in the global balance, but all internal chemio-physical phenomena are neglected. The feedstock is assumed to be completely homogeneous and to be fed at a constant rate. It is assumed also that the temperature of the sludge inside of the digester remains constant throughout the digestion period, but since the same assumption is posited for the heating water, this amounts to adopting an average and constant value for the thermal losses from the digester, which in fact depend on the external temperature as well.

\subsubsection{Parameters Definition}

In order to analyze and model the process, some parameters were defined that characterize the inlet feedstock and dispense the user of the task of defining the (often unknown) real chemical composition of the biological substrate. Other suitable fundamental parameters of the anaerobic digestion process were defined that allow the evaluation of the biogasification rate on the basis of the feedstock chemo-physical characteristics.

To more accurately describe the process and to evaluate the thermal and electric demands of an AD, some other parameters were defined that identify the type of process (perfectly stirred or not), the geometry of the reactor and some of its constructive characteristics.

\subsubsection{Feedstock Definition}

To define the characteristics of the feedstock without requiring a complete knowledge of its (often unknown) chemical composition, four global parameters have been used in this work: the amount of water (Water) and dry matter $(\mathrm{DM})$ in the feed, the organic matter $(\mathrm{OM})$ contained in the dry fraction and the volatile organic matter (VOM) content of this organic fraction; all of these parameters are expressed as mass fractions and measured in percent.

This approach enables the simulator to accept as feedstock any kind of organic degradable material for which the four above characteristics are known: notice that these values are easily recovered from the existing literature for a large amount of suitable biomass stocks (EPA, 2010; Fergusen \& Mah, 2006).

\subsubsection{Process Type}

To characterize the process on the basis of its feedstock handling system, a mixing power $(M P)$ parameter has been added that represents the energy in $\mathrm{kW} / \mathrm{m}^{3}$ provided by the mixer to the substrate. This parameter identifies whether the process is completely stirred or of the plug flow type

\subsubsection{Retention Time}

The amount of biogas produced in an anaerobic digestion process is highly dependent on the residence time of the substrate in the reactor. There is a relatively large amount of data, usually published in the form of graphs, that provide the percentage of biogas extracted from VOM versus the number of days (Retention Time) in which the substrate remains in a reactor operating at a certain temperature (see for example Rajendran et al. (2012)). In our model, a Retention Time parameter has been included to allow the user to prescribe the duration of the digestion process (in days). Notice that this parameter, together with the mass flow rate at the inlet, also determines the size of the reactor.

\subsubsection{Thermal Conditions}

In practice, there exist two types of anaerobic digestion processes, and they depend on the family of bacteria involved in it, thermophile or mesophile: the respective type of process is identified by the operating temperature, $55^{\circ} \mathrm{C}$ or $35{ }^{\circ} \mathrm{C}$ (Song et al., 2004). For this reason, the model provides the user with the possibility of selecting which kind of process the software is to simulate, and this is done via a parameter called Bacteria Type. This parameter is also used to evaluate the thermal request of the reactor, that depends both on the heat losses that must be made up for to maintain the desired temperature and on the heat demand to bring the feedstock to the operating temperature.

\subsubsection{Reactor Geometry and Constructive Characteristics}

In order to perform an accurate calculation of the thermal requests of the $\mathrm{AD}$, three additional parameters must be specified by the user: the geometry of the reactor box (prismatic or cylindrical), the thickness of the reactor walls and the transmittance of the wall material; these parameters, together with the reactor chamber size, make it possible to evaluate the thermal losses of the entire structure, the length of the heating pipes and their specific losses, so that the total heat demand can be assessed.

\subsubsection{Fundamental Equations}

To describe the equations used to define the AD model it is useful to think of the equation system as if it were divided into three different blocks that represent respectively the biogasification process, the thermal and electrical demands of the $\mathrm{AD}$ and its energy and exergy balances.

\subsubsection{Biogasification Process}

It is possible to link the quantity of produced biogas directly to the VOM fraction of the feedstock Kiely (1998); but for an exact evaluation it is necessary to consider the retention time (as explained in Section 3.1.2.3). On the basis of the graphs available in Rajendran et al. (2012) and Song et al. (2004), two equations were developed, one for the thermophile and one for the mesophile process:

Thermophile process:

$\eta_{r}=100-160 / t_{R}$

Mesophile process:

$\eta_{r}=100-300 / t_{R}$

In Eqs. (1) and (2), $\eta_{r}$ is the Reaction Efficiency , i.e. the mass fraction of VOM that for a certain retention time $t_{R}$ (measured in days) is transformed in biogas. 
The graphs obtained by fitting the experimental data provided in Rajendran et al. (2012) are plotted in Figure 2.

Once $\eta_{\mathrm{r}}$ and the composition of the feedstock are known, the flow rate of the produced biogas is given by the relation:

$$
m_{B}=m_{F} \cdot D M \cdot O M \cdot V O M \cdot \eta_{r}[\mathrm{~kg} / \mathrm{s}]
$$

where $m_{B}$ and $m_{F}$ are biogas and feedstock mass flow rates, respectively.

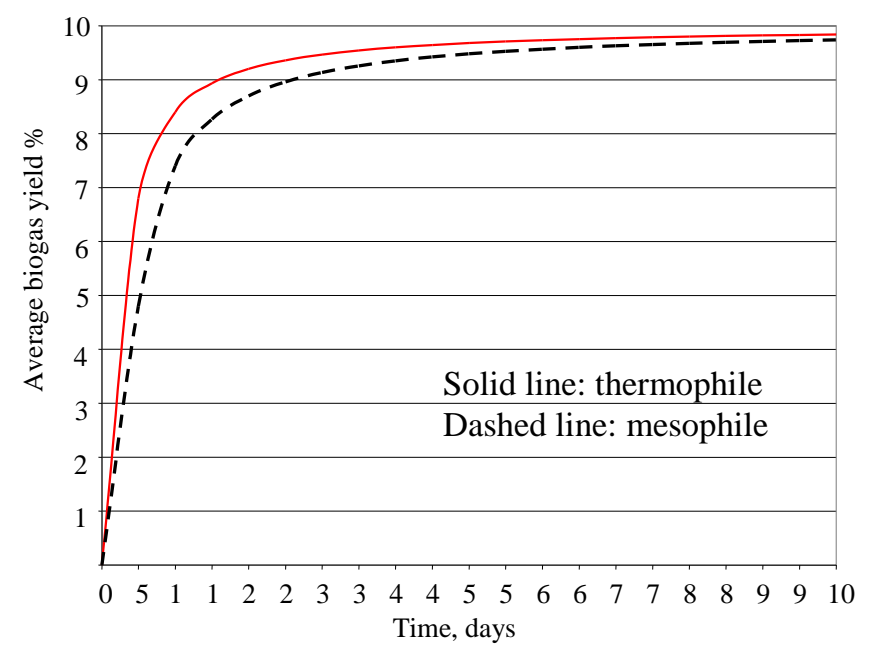

Figure 2. Graph of the functions implemented in this study to reproduce the behavior of the average biogas yield vs retention time (adapted from Rajendran et al. (2012)).

As for the composition and physical properties of the produced biogas, standard literature values (IEA, 2005; Petersson, 2009), shown in Table 1, have been used in this study:

Table 1. Typical Biogas Composition.

\begin{tabular}{ll} 
& Table 1. Typical Biogas Composition. \\
\hline Species & Volume composition $(\%)$ \\
\hline $\mathrm{CH}_{4}$ & 59 \\
$\mathrm{CO}_{2}$ & 40 \\
$\mathrm{H}_{2} \mathrm{~S}$ & $1 \times 10^{-6}$ \\
$\mathrm{~N}_{2}$ & $5 \times 10^{-1}$ \\
$\mathrm{H}_{2} \mathrm{O}$ & $5 \times 10^{-1}$ \\
\hline
\end{tabular}

The most important physical value for the purpose of this study is the lower heating value (LHV), that is assumed equal to $16,300 \mathrm{~kJ} / \mathrm{kg}$ or $20,863 \mathrm{~kJ} / \mathrm{Nm}^{3}$.

From the biogas mass flow rate it is possible to calculate the amount of Digested Substrate (DS) that exits the AD and represents the discharge stream of the process:

$m_{D S}=m_{F}-m_{B}$

Since in our lumped model the chemical composition of this stream does not affect the simulations results, it has been assumed that it fits the specifications of an "agricultural soil".

\subsubsection{Thermal and Electrical Requirements}

The thermal demand of an AD stems from the need of (Kiely, 1998; Reynolds \& Richards, 1996; Tchobanoglous et al., 2003):
1. Raising the temperature of the incoming feedstock to that of the digestion tank;

2. Compensating for the heat losses through the walls, floor and roof of the digester;

3. Making up for the losses that occur in the heating system (insulation losses from the pipes).

The amount of heat used to bring the inlet feedstock from the environment temperature to the plant operating temperature has been evaluated assuming that since the water content of the feedstock is at least $70 \%$, a specific heat calculated as the weighted average of $c_{p, w a t e r}$ and $c_{p, M S W}$ introduces a negligible error in the calculations; this assumption leads to the relation:

$Q_{f}=m_{F} \cdot c_{p, \text { average }} \cdot\left(T_{\text {reaction }}-T_{0}\right)$

Notice that $\mathrm{Q}_{\mathrm{f}}$ does not include the heat released by the reaction, because it is assumed that the reaction does not begin until the feedstock has reached the specified reaction temperature.

In order to evaluate the heat losses, the following relations were used:

\section{Reactor chamber size $\left(\mathrm{m}^{3}\right)$ :}

$V=m_{F} t_{R} / \rho_{F}$

where $m_{F}, t_{R}$ and $\rho_{F}$ are inlet mass flow rate, retention time and feedstock density, respectively.

Box overall surface $\left(\mathbf{m}^{2}\right)$ : From geometric considerations (size, shape and wall thickness);

\section{AD thermal requirements $(\mathrm{kW})$ :}

$Q_{A D}=S_{D} \cdot U \cdot\left(T_{\text {reaction }}-T_{0}\right)$

where $S_{D}, U$ are box surface, wall transmittance, respectively.

Once the surface extension of the AD box is known, it is possible to evaluate the thermal losses and the total pressure loss in the heating pipes. The following assumptions are posited:

- The piping covers $3 / 4$ of the box surface (real AD's have a portion designated to work as a backup tank for the produced biogas).

- The heating system is modular, with base module of 2 x 2 m;

- Every module has $40 \mathrm{~m}$ of piping installed;

- Every module has 20 elbows;

- Every module has a global transmittance of $2 \times 10^{-4}$ $\mathrm{kW} /\left(\mathrm{m}^{2}{ }^{\circ} \mathrm{K}\right)$;

- The hydraulic system is divided in 4 main sections;

- The pipes have a surface/length ratio of $0.175 \mathrm{~m}^{2} / \mathrm{m}$, typical of a $2 "(5 \mathrm{~cm})$ pipe.

The thermal losses in the piping system $\left(\mathrm{Q}_{\mathrm{P}}\right)$ have been evaluated with a relation similar to Eq. (5), while the pressure losses in the pipes are computed by a specific routine of the simulator. 


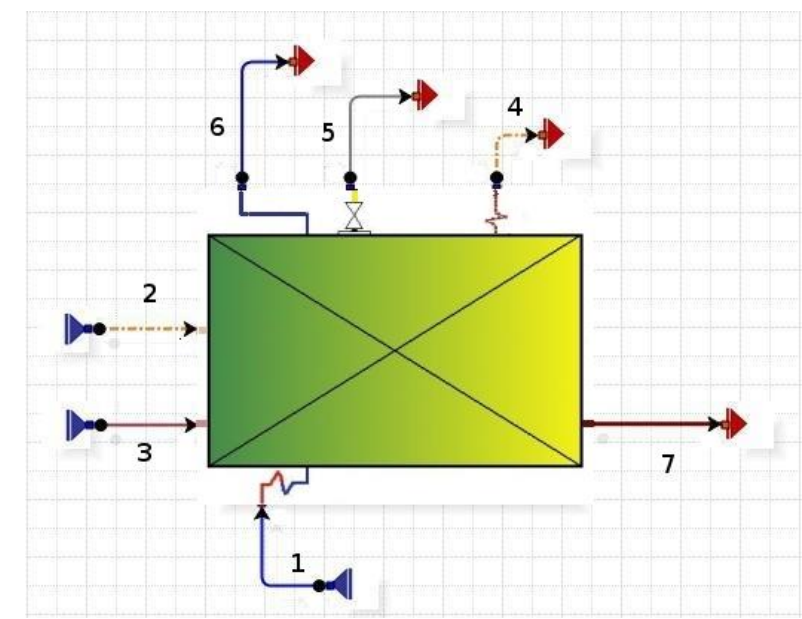

1) Heating water in; 2) Electric power in; 3) Feedstock in;

4) Thermal losses; 5) Biogas out; 6) Heating water out;

7) Digested substrate out.

\section{Figure 3. Input and output streams for the AD.}

In this model, the thermal demand of the $\mathrm{AD}$ is completely satisfied by an external hot water stream, whose mass flow rate, inlet and outlet temperature are system variables. The three terms that originate the heat demand are summed together to obtain a single value:

$Q_{t o t}=Q_{f}+Q_{A D}+Q_{p}$

and then the water mass flow rate is evaluated with:

$$
m_{w A D}=\left[Q_{t o t} /\left(h_{\text {winAD }}-h_{\text {wouAD }}\right)\right]
$$

where $h_{\text {winAD }}$ and $h_{\text {woutAD }}$ are the values of specific enthalpy at the inlet and outlet for the hot water stream.

For both processes, termophile and mesophile, it is assumed throughout this simulation that the inlet and outlet water temperatures are respectively equal to $90{ }^{\circ} \mathrm{C}(363.15$ $\mathrm{K})$ and $60{ }^{\circ} \mathrm{C}(333.15 \mathrm{~K})$; these assumptions are made considering that the anaerobic digester (AD) is coupled with an internal combustion engine (ICE) and that the ICE cooling water temperatures are normally in this range.

The electrical demand, in the context of the present work, includes only the mixer, and therefore a relation has been introduced to express it in terms of the reactor chamber size, the mixing power and the mechanical efficiency of the drive train, in $\mathrm{kW}$ :

$$
P_{m}=V \cdot M P / \eta_{m}
$$

In this simulation MP is assumed $0.01 \mathrm{KW} / \mathrm{m}^{3}$, since the reactor does not need a powerful mixer but only a slowly rotating bladed shaft used to free the gas bubbles trapped in the substrate.

\subsubsection{Energy and Exergy Balances}

The energy balances are used to define several process parameters, as discussed in 3.1.3.2, and also to estimate the LHV of the Digested Substrate through the relation:

$$
L H V_{D S}=\frac{m_{F} * L H V_{F}-m_{B} * L H V_{B}}{m_{D S}}
$$

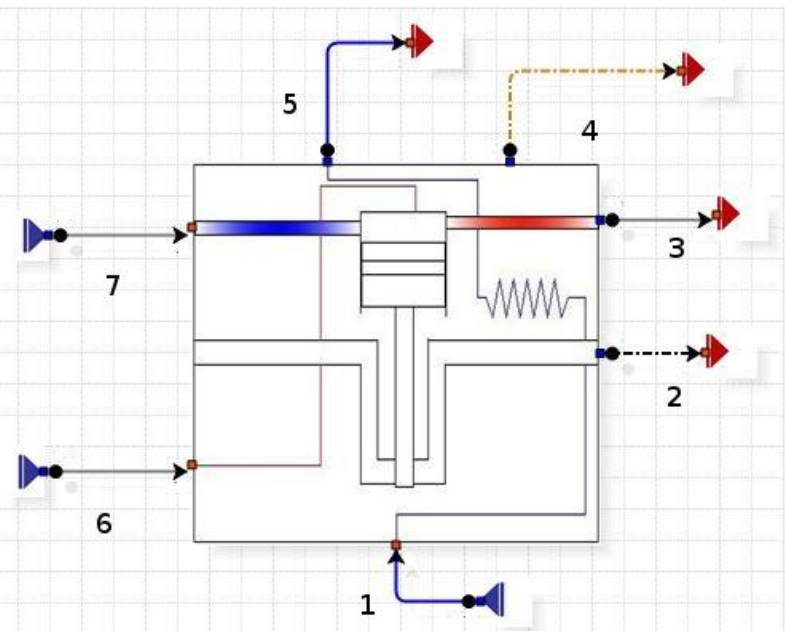

1) Cold water; 2) Shaft power; 3) Exhaust gas;

4) Thermal losses; 5) Hot water; 6) Fuel; 7) Air.

\section{Figure 4. Input and output streams for the ICE.}

The value for the LHV of the feedstock is evaluated with Milne's formula using a standard chemical composition Di Maria et al. (n.d.). Notice that this may result in a poor approximation, because there is no proof that the LHV of the digestate is equal to its exergy, and the latter could be calculated on the basis of the chemical composition using Szargut's method. Since chemical analyses of digestates are not available, this was though a necessary assumption.

Milne's formula uses the chemicals mass fraction of $\mathrm{C}$, $\mathrm{H}, \mathrm{O}, \mathrm{N}, \mathrm{S}$ and the ash fraction:

$$
\begin{aligned}
& H H V_{\text {Mine } e}=0.341 \times C+1.322 \times H-0.12 \times O- \\
& 0.12 \times N+0.0686 \times S-0.0153 \times \text { ash }
\end{aligned}
$$

To extrapolate the LHV on dry basis the following relation was used:

$$
L H V_{d r y}=H H V_{M i \ln e}-2.442 \times 8.936 \times H \div 100
$$

In Di Maria et al. (n.d.) a typical composition used in some cases to evaluate the biomasses is $\mathrm{C}_{6} \mathrm{H}_{9.6} \mathrm{O}_{3.5} \mathrm{~N}_{0.28} \mathrm{~S}_{0.2}$.

To evaluate the exergy efficiency and the exergy destruction, a Second Law analysis of the component has been performed. Identifying the streams as in Figure 3, the total exergy input (TEI) is:

$T E I=E 3+E 2+(E 1-E 6)$

with: $\quad \dot{E}_{\mathrm{i}}=\dot{m}_{i} * e_{i}[\mathrm{~kW}]$, total exergy rate of stream " $i$ ".

The definition of the desired exergy output (DEO) is not unequivocal and depends on the Process Engineer decision:

a) The DS can be considered as a waste of the production process, in which case

$D E O=E 5$

b) Alternatively, the DS can be considered as a product, because it may be used downstream as a compost or as a low-grade fuel. In this case

$D E O=E 5+E 7$ 
The AD Second Law efficiency is then computed as:

$\eta_{I I}=\frac{D E O}{T E I}=\frac{E_{\text {useful }, \text { out }}}{E_{\text {used }, \text { in }}}=1-\frac{E_{\text {destruction }}}{E_{\text {used }, \text { in }}}$

\subsection{Internal Combustion Engine}

\subsubsection{Model Definition}

A lumped model of an internal combustion engine (ICE) has been developed as well: this model is not intended to simulate the operating details of an ICE, but only to compute the net mechanical power obtainable for an assigned fuel mass flow rate and with a given fuel chemical composition. The model also includes the calculation of the engine cooling water system, considered here as a "hot water source" for the digester.

\subsubsection{Parameters Definition}

There are only two parameters that the user must assign:

- Global efficiency $\left(\eta_{\text {eng }}\right)$, i.e., the ratio of the generated shaft power to the fuel input power;

- First law co-generation efficiency, i.e., the ratio of the mechanical plus the thermal power to the fuel input power.

\subsubsection{Fundamental Equations}

As for the AD, also for the ICE the system of equations can be split into three different parts that represent respectively the shaft power output, the thermal power output and the energy and exergy balances.

\subsubsection{Mechanical Power Output}

The available shaft power output provided by the ICE is given by:

$$
P_{\text {shaft }}=m_{f} \cdot L H V \cdot \eta_{\text {eng }}
$$

\subsubsection{Thermal Power Output}

To estimate the available thermal power produced by the ICE considered as a co-generation unit, the hot water mass flow rate is calculated as a function of the given inlet and outlet temperatures.

The water mass flow rate is given by Cosić et al. (2011):

$$
\begin{aligned}
& m_{w}=\frac{Q_{\text {out }} \eta_{H E}}{h_{w, \text { out }}-h_{w, \text { in }}} \\
& =\frac{\left[m_{a} h_{a}+m_{f}\left(h_{f}+L H V\right)\right]\left(1-\eta_{\text {eng }}\right) \eta_{H E}}{h_{w, \text { out }}-h_{w, \text { in }}}
\end{aligned}
$$

in which the term $m_{a} h_{a}$ is negligible for all practical purposes, the term $h_{w, \text { in }}$ is the enthalpy of stream 1 in figure 4 and the term $h_{w, o u t}$ is the enthalpy of stream 5 in the same figure.

The values adopted for the efficiency are: $\eta_{\text {eng }} 41 \%$ and $\eta_{\mathrm{HE}} 85 \%$, standard values for these applications.

In this simulation the temperatures considered are: for the inlet water is $60{ }^{\circ} \mathrm{C}(333.15 \mathrm{~K})$ and for the outlet water $90{ }^{\circ} \mathrm{C}(363.15 \mathrm{~K})$. These temperature range represents an accepted standard for the cooling water of the internal combustion engine (ICE)

\subsubsection{Energy and Exergy Balances}

To evaluate the ICE exergy efficiency and the exergy destroyed therein, the same approach followed for the Digester is adopted: with reference to Figure 4, The total exergy input (TEI) is:

$T E I=E 6+E 7$

with $\mathrm{E}_{\mathrm{i}}=m_{i} e_{i}[\mathrm{~kW}]$, total exergy of a stream; whereas the desired exergy output (DEO) is given by the shaft power plus the difference in the exergy content of the hot- and cold water:

$D E O=E 2+(E 5-E 1)$

Since average temperature and composition of all streams are known, it is possible to perform an exergy analysis of a standalone I.C. Engine, in which case obviously the DEO is only the mechanical E2.

\subsection{Validation of the Models}

Using the scarce literature data (Tabatabaei et al., 2010) on real plants (generally composed of one or more $\mathrm{AD}$ coupled with several ICE), the component models have been tested and found to reproduce closely the behavior of the real units: the rms of the deviations of the simulated vs. the experimental data is below $10 \%$. Neither the calibration data nor the comparison are reported here (see Di Maria et al. (n.d.) and Petersson (2009) for details).

\section{Results and Discussion}

\subsection{Data Definition}

The simulations are performed on the basis of a data set representative of a typical Italian agricultural and foodfarming district, with a number of inhabitants between 200000 and 500000.

The average data for the production of MSW in Italy (Clark Energy, n.d.) indicate as a reasonable estimate 550 $\mathrm{kg} / \mathrm{y}$ of waste per person, $38 \%$ of this amount being the organic fraction. The real amount of available organic fraction is strictly dependent on the collection system adopted, but using the available data it is reasonable to assume that a representative value amounts to $50 \%$ of the dry weight.

This assumption is needed to evaluate the "size" (yearly capacity) of the AD plant, and to select the size of the ICE in relation to the mass flow rate of the biogas.

To improve the quality of the solid output from the AD (i.e., to improve its quality as a fertilizer for agricultural use), it is desirable to mix to the MSW a certain amount of green fibers to give the compost the correct structure; normally this quantity amounts to $30 \%$ of the total plant capacity, but since the focus of this topic is to perform an analysis of a system that uses basically MSW, in all calculations a 50/50 mix has been assumed.

The food-farming waste used in this work is modeled assuming a "typical" composition: the stream is a mix of $30 \%$ maize silage, $10 \%$ fruit marc and $60 \%$ vegetable waste. Using the data available in Murphy \& Power (2009) and with the procedure described in 3.2.3.3, the proximate analysis of each one of the three types of feedstock for which the calculations were run is shown in Table 2: 
Table 2. Proximate Analysis of the Three Considered Feedstock Streams.

\begin{tabular}{cccc}
\hline & MSW & $\begin{array}{c}\text { Food-Farming } \\
\text { Waste }\end{array}$ & $\begin{array}{c}\text { MSW + } \\
\text { FFW }\end{array}$ \\
\hline Dry Matter (\%) & 30 & 25 & 27,5 \\
Water (\%) & 70 & 75 & 72,5 \\
Organic Matter (\%) & 80 & 85 & 82,5 \\
Volatile Organic Matter & & 78 & 79 \\
$(\%)$ & 80 & 850 & 825 \\
Density $\left(\mathrm{kg} / \mathrm{m}^{3}\right)$ & 800 & 2.900 & 3.458 \\
\hline LHV (kJ/kg), dry basis & 4.016 & &
\end{tabular}

\subsection{Mass and Energy Balances}

The mass and energy balances are summarized in Tables 3 and 4 and Figure 5 represents the result of this sensitivity analysis with respect to the feedstock composition; the simulations have been performed for the feedstocks defined in 4.1; the size of AD is 36,000 ton/y and the chosen process is thermophile at $55^{\circ} \mathrm{C}$.

Table 3. Output Stream and Biogas Production Related to Input Type.

\begin{tabular}{ccccc}
\hline & $\begin{array}{c}\text { MSW } \\
\text { (tons/y) }\end{array}$ & $\begin{array}{c}\text { MSW + } \\
\text { FFW } \\
\text { (tons/y) }\end{array}$ & $\begin{array}{c}\text { FFW } \\
\text { (tons/y) }\end{array}$ & $\begin{array}{c}\text { Difference } \\
\text { percentage } \\
\text { min/Max }\end{array}$ \\
\hline $\begin{array}{c}\text { Produced } \\
\text { Biogas } \\
\text { Output } \\
\text { Stream } \\
\text { (DS) }\end{array}$ & $6,307.2$ & $5,991.8$ & $5,613.4$ & $11 \%$ \\
\hline
\end{tabular}

Table 4. Mechanical Energy Production Related to Input Type.

\begin{tabular}{ccccc}
\hline & $\begin{array}{c}\text { MSW } \\
(\mathrm{MWh} / \mathrm{y})\end{array}$ & $\begin{array}{c}\mathrm{MSW}+ \\
\mathrm{FFW} \\
(\mathrm{MWh} / \mathrm{y})\end{array}$ & $\begin{array}{c}\text { FFW } \\
(\mathrm{MWh} / \mathrm{y})\end{array}$ & $\begin{array}{c}\text { Difference } \\
\text { percentage } \\
\text { min/Max }\end{array}$ \\
\hline $\begin{array}{c}\text { Mechanical } \\
\text { Energy }\end{array}$ & $12.149,77$ & $11.343,88$ & $10.485,42$ & $13.69 \%$ \\
\hline
\end{tabular}

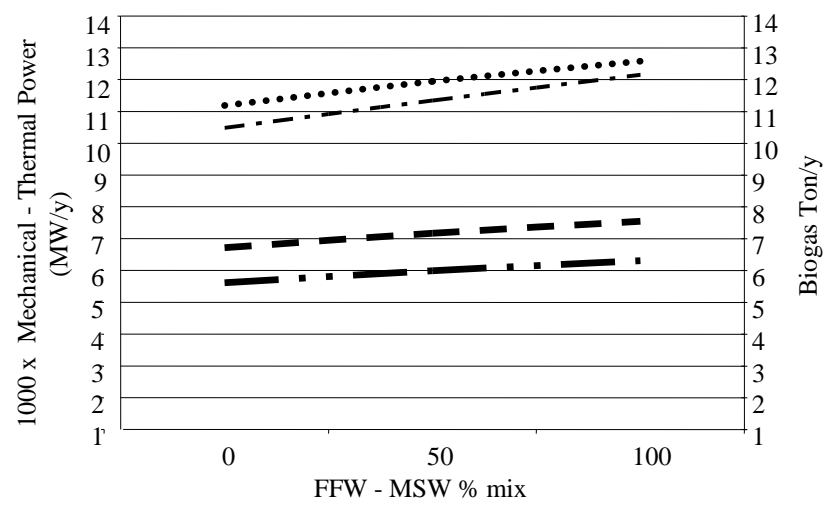

- - Mechanical Power $=-$ - Thermal Power Residual ........ Thermal Power Total — Biogas

Figure 5. Sensitivity of the production volume to the feedstock mix.

To evaluate the amount of MWh/y produced in terms of mechanical energy, since the simulator gives the amount of $\mathrm{kJ}$ produced, the conversion was made by multiplicating the energy output by the total amount of seconds in one year $(8760 * 60=31,536,000)$. This neglects of course entirely the plant downtime.
Table 5. Thermal Energy Production Related to Input Type.

\begin{tabular}{ccccc}
\hline & $\begin{array}{c}\text { MSW } \\
(\mathrm{MWh} / \mathrm{y})\end{array}$ & $\begin{array}{c}\text { MSW + } \\
\text { FFW } \\
(\mathrm{MWh} / \mathrm{y})\end{array}$ & $\begin{array}{c}\text { FFW } \\
(\mathrm{MWh} / \mathrm{y})\end{array}$ & $\begin{array}{c}\text { Difference } \\
\text { percentage } \\
\text { min/Max }\end{array}$ \\
\hline $\begin{array}{c}\text { Thermal } \\
\text { Energy }\end{array}$ & $12.575,01$ & $11.946,26$ & $11.191,76$ & $11 \%$ \\
\hline
\end{tabular}

Figure 6 presents a sensitivity analysis with respect to the retention time: the input stream is in this case pure MSW (the mass flow rate is fixed) for which the nominal retention time is 29 days.

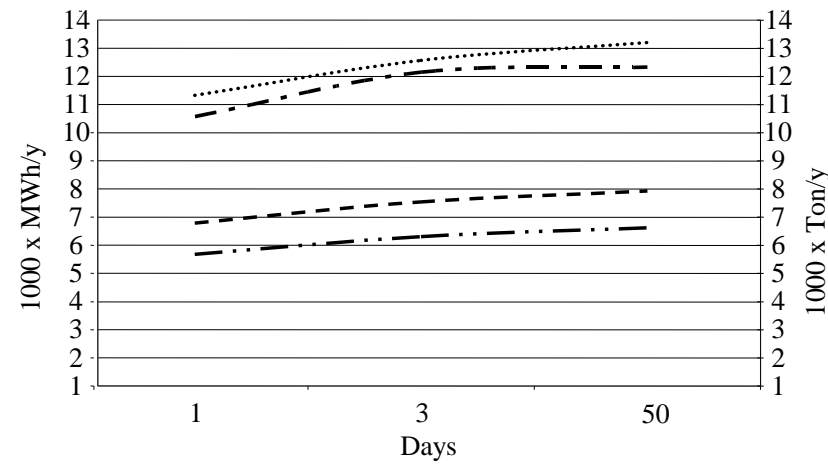

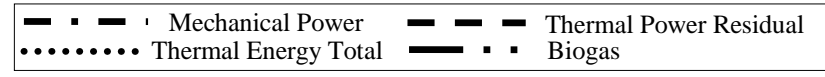

Figure 6. Sensitivity of the production volume to the retention time.

\subsection{Exergy analysis}

The exergy analysis is presented here first considering the whole plant (AD and the ICE coupled with each other), and then at a more disaggregated level considering each component by itself.

Simulations have been performed considering the three feedstock streams described in 4.1 and two different scenarios:

a) The DS is considered as a discharge;

b) The DS is considered as a co-product.

Figures 7 and 8 show the exergy efficiency and the exergy destruction of the whole plant, Figures 9 and 10 the same for the AD.

For the ICE operating in co-generating mode, the average values resulting from the exergy analysis, considering the simulated cases, are:

- Mechanical Power: 1200 kW

- Exergy efficiency: 0.55

- Exergy Destruction: $1000 \mathrm{~kW}$

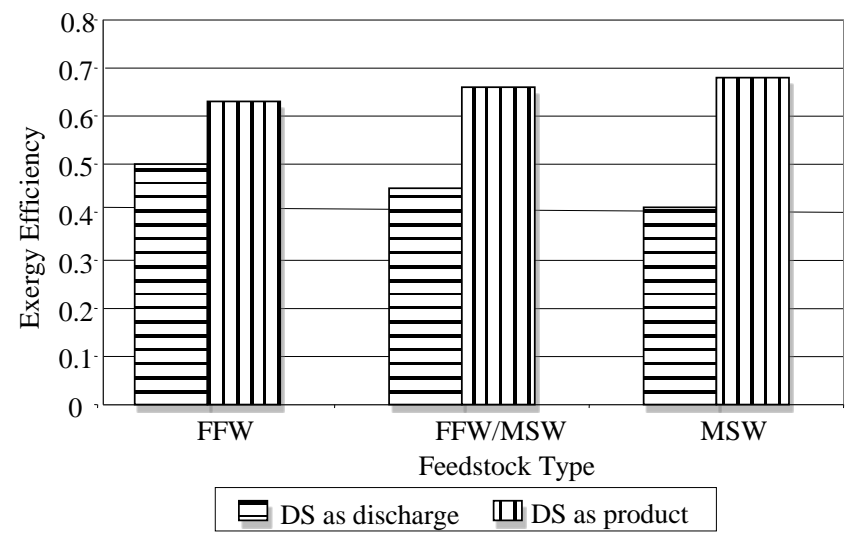

Figure 7. Exergy efficiency of the plant for different feedstock mixes. 


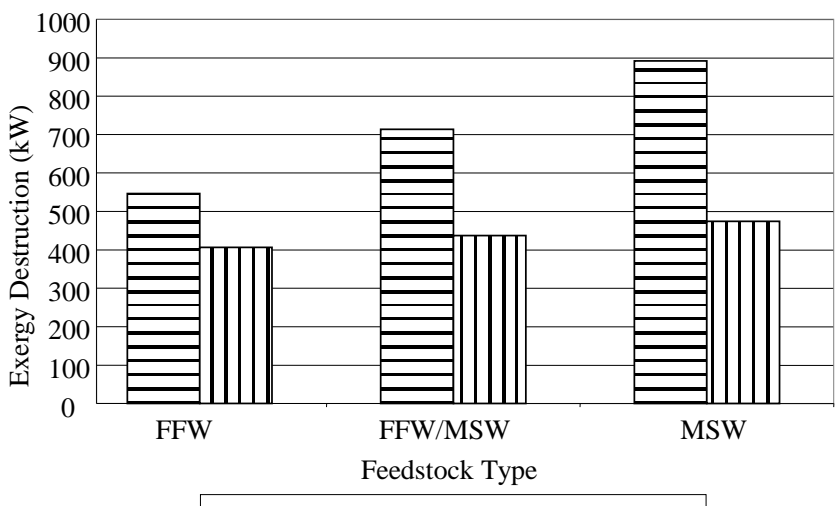

DS as discharge $\square$ DS as product

Figure 8. Exergy destruction of the plant for different feedstock mixes.

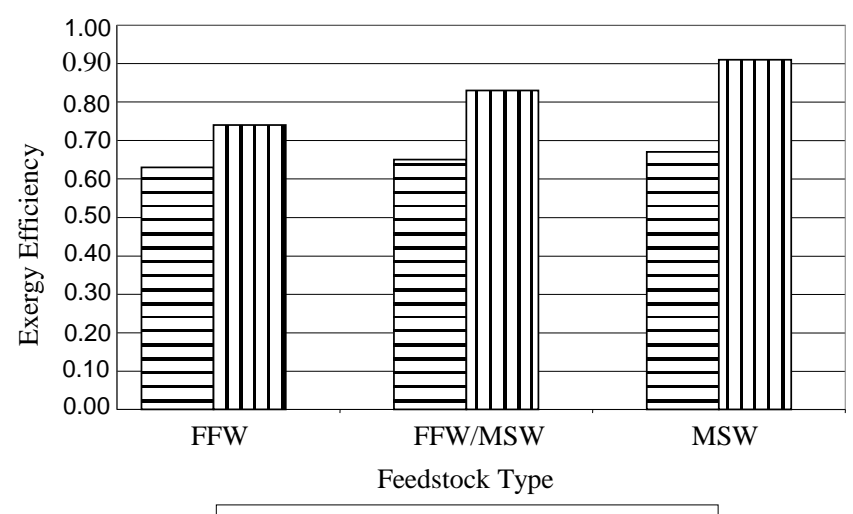

DS as discharge एा DS as product

Figure 9. Exergy efficiency of the AD for different feedstock mixes.

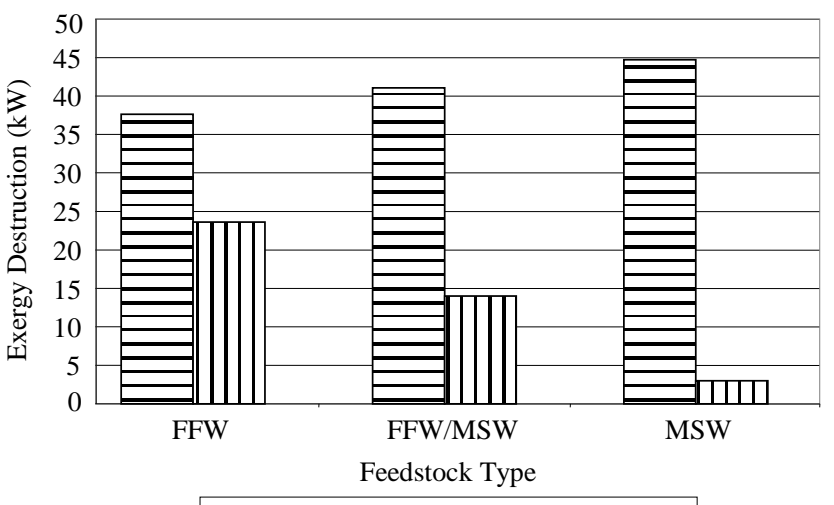

$\equiv \mathrm{DS}$ as discharge $\square \mathrm{DS}$ as product

Figure 10. Exergy destruction in the AD for different feedstock mixes.

\subsection{Analysis and Discussion}

The results of the simulations presented in Figure 5 show that, since a variation in the mixture composition brings about a variation of the percent of dry matter (in this case, DM grows from FFW to FFW/MSW to MSW) and given that if in the FFW stream the percent of organic matter is higher and the percent of volatile organic is quite the same, the most valuable stream to produce biogas is the one composed only of MSW.

Figure 6 shows the influence of the retention time, with a constant mass flow rate at the inlet, on the production of biogas: this value is strictly related to the number of days of retention in the reactor and, after 30 days the increase in production is minuscule and does not justify a longer retention. Considering a constant volume of the reaction chamber, as realized in the major amount of the real plants, the results demonstrate that in case of a decrease of the retention time, the production is lower but the amount of treatable feedstock grows in inverse relation with the ratio between the actual retention time and the plant design retention time. Conversely, if the retention time increases the total amount of treatable inlet decreases with the same ratio.

The exergy analysis, represented in Figures 6 and 7 for the whole plant, indicates a direct relation between the efficiency and the lower heating value of the inlet stream; the two analyzed situations show that if the DS is considered as a discharge the efficiency decreases when the LHV of the input stream increases, while if it is considered as a co-product the efficiency grows with the LHV.

The destroyed exergy $\dot{\mathrm{E}}_{\square}$ increases with the LHV of the input stream if the DS is a waste, whereas if the DS is a coproduct $\dot{\mathrm{E}}_{\square \square}$ is approximately constant in all situations, the differences (in a range of 400 to $470 \mathrm{~kW}$ ) being mostly due to the ICE; the simulations are performed here at constant input mass flow rate, so that the size -and therefore the absolute value of the exergy destroyed in the engine per unit mass of input- is larger for the stream that produces more biogas.

At a more disaggregated level, the exergy analysis of the AD shows that the higher the LHV of the feed stream, the higher the efficiency; if the DS is a waste, the difference between the $\dot{\mathrm{E}}_{\square}$ of the three mixes is small, but if it is considered a co-product this difference varies according to the variations of the LHV of the DS and with the largest amount of biogas produced. The values of the destroyed exergy in the AD explains how the quality of the input affects the performance of the component: for a fixed mass flow rate, a stream with a lower amount of water requires a smaller amount of thermal power to reach the operating temperature; furthermore using a high LHV feed the DS, if considered as a product, has a higher LHV with all the other requirements of the components that remains the same regardless the type of inlet composition.

\section{Conclusions}

The performance and the exergetic behavior of an anaerobic digester coupled with a internal combustion engine operating in co-generation mode were simulated via a process simulator for which both models were developed. The relevant results are presented below.

1. The amount of biogas and of mechanical and thermal power produced by the plant are directly related to the water content of the feed; furthermore for a stream of a given composition, these values are significantly affected by the retention time.

2. The plant exergy efficiency analysis, and also the related destroyed exergy, demonstrate that if the digested substrate is considered as a co-product, its non-negligible exergy content leads to higher values of the efficiency.

3. At a more disaggregated level, while the ICE retains the same efficiency for all simulated cases, the AD efficiency increases with the DM content of the input biomass, and its "optimal engineering performance" is strictly related to the amount of produced biogas (or to the amount of water in the feed stream) and to the projected use of the digested substrate. 


\section{Nomenclature}

$\begin{array}{ll}\dot{E}_{i} & \text { Exergy destruction rate, } \mathrm{kW} \\ E & \text { Exergy flow, } \mathrm{kW} \\ h & \text { Specific enthalpy, } \mathrm{kJ} / \mathrm{kg} \\ \mathrm{LHV} & \text { Lower Heating Value, } \mathrm{kJ} / \mathrm{kg} \\ M & \text { Mass flow rate } \\ M P & \text { Power content (output) per unit volume, } \mathrm{kW} / \mathrm{m}^{3} \\ P & \text { Power, W } \\ Q_{l} & \text { Heat loss, } \mathrm{kW} \\ S_{D} & \text { External Digester surface, } \mathrm{m}^{2} \\ t_{R} & \text { Retention time, days } \\ T_{0} & \text { Environmental temperature, } \mathrm{K} \\ U & \text { Digester wall total thermal transmittance, } \\ & \left.\text { kW/(m }{ }^{2} \mathrm{~K}\right) \\ V & \text { Digester volume, } \mathrm{m}^{3} \\ \mathrm{H} & \text { Efficiency } \\ \eta_{\text {eng }} & \text { ICE efficiency, } \mathrm{P} /(\mathrm{mLHV}) \\ \eta_{\mathrm{HE}} & \text { Heat Exchanger efficiency, } \mathrm{Q}_{\text {useful }} / \mathrm{Q}_{\mathrm{used}} \\ \mathrm{P} & \text { Density, kg/m }{ }^{3}\end{array}$

$\begin{array}{ll}\text { Suffixes } \\ \text { a } & \text { air } \\ \text { AD } & \text { digester } \\ \text { B } & \text { biogas } \\ \text { DS } & \text { Digested substrate } \\ \text { el } & \text { electrical } \\ \text { eng } & \text { engine } \\ \text { f } & \text { fuel } \\ \text { F } & \text { feedstock } \\ \text { HE } & \text { Heat exchanger } \\ \text { II } & \text { Second law } \\ \text { l } & \text { loss } \\ \text { m } & \text { mechanical } \\ \text { r } & \text { reaction } \\ \text { shaft } & \text { At the shaft } \\ \text { W } & \text { Engine water } \\ \text { Wad } & \text { AD water } \\ \text { Win } & \text { AD water in } \\ \text { Wout } & \text { AD water out }\end{array}$

\section{References:}

Archea (2009). Archea Biogas. Retrieved January 10, 2009, from www.archea.de.

Batstone, D. J., Keller, J. et al. (2002). Anaerobic Digestion Model No. 1 (ADM1). London, UK: IWA Publishing.

Clark Energy. (n.d.). GE Jenbacher Biogas Engines. Retrieved September 3, 2012, from www.clarkeenergy.com.

CIRCUS (2013). Camel Pro ${ }^{\circledR}$. Retrieved September 2008, from www.turbomachinery.it/software.html.

Ćosić, B., Stanić, Z., Duić, N. (2011), Geographic distribution of economic potential of agricultural and forest biomass residual for energy use: Case study Croatia, Energy, 36, 2017-2028.

Di Maria, F., Benavoli, M., Zoppitelli, M. (n.d.). Energy recovery from treatment processes of food-and agrofood industrial organic waste, Dept. Industrial Engineering, Univ. of Perugia, Italy (in Italian).
EPA (2010). Biodigester Update, Retrieved September 3, 2012, from http://www.epa.gov/agstar/documents/.

Fergusen, T., Mah, R. (2006) Methanogenic bacteria, in Anaerobic digestion of biomass, Chynoweth, D. Y \& Isaacson, R. Eds. Elsevier Applied Science series.

IEA Bioenergy. (2005). Task 24: Energy from biological conversion of organic waste. Biogas Upgrading and Utilization.

Jewell, W., Cummings, R., Richards, B. (1993), Methane fermentation of energy crops: Maximum conversion kinetics and in situ biogas purification, Biomass and Bioenergy, 5, 261-278.

Kiely, G. (1998). Environmental Engineering, Boston: Irwin, McGraw-Hill.

Kompogas AG (2009). Axpo Kompogas. Retrieved January 10, 2009, from www.kompogas.ch.

Lanzafame, R., Messina, M. (2000). A New Method for the Calculation of the Enthalpy of Gases. IECEC 2000. Proceedings of Energy Conversion Engineering Conference and Exhibit, 200. (IECEC) 35th Intersociety, vol 1, 318-328.

Murphy, J. D., Power, N. (2009), Technical and economic analysis of biogas production in Ireland utilising three different crop rotations, Applied Energy, 86, 25-36.

ONR (2008). Osservatorio Nazionale sui Rifiute. Retrieved September 9, 2008, from www.osservatorionazionalerifiuti.it.

Petersson, A. (2009). Biogas as transport fuel - Upgrading technique and application. Swedish gas centre. Retrieved from www.sgc.se.

Rajendran, K., Aslanzadeh, S., Taherzadeh, M. J. (2012), Household biogas digesters - A review, Energies, 5, 2911-2942.

Reynolds, T. D., Richards, P. A. (1996). Unit Operations and Processes in Environmental Engineering, ( $2^{\text {nd }}$ ed.). Boston: PWS Publishing Company.

Richards, B., Cummings, R. J., Jewell, W. J. (1991), High rate low solids methane fermentation of sorghum, corn and cellulose, Biomass and Bioenergy, 1, 249-260.

Richards, B. K., Cummings, R. J., White, T. E., Jewell, W. J. (1991), Methods for kinetic analysis of methane fermentation in high solids biomass digester, Biomass and Bioenergy, 1, 65-73.

Richards, B., Herndon, F. G., Jewell, W. J., Cummings, R. J., White, T. E. (1994), In situ methane enrichment in methanogenic energy crop digesters, Biomass and Bioenergy, 6, 275-282.

Rota Guido srl (2009) . Rota Guido. Retrieved January 10, 2009, from www.rotaguido.it/prodotti/recuperobiogas.html

Song, Y.C., Kwon, S.J., Woo, J.H. (2004), Mesophilic and thermophilic temperature co-phase anaerobic digestion compared with single-stage mesophilic- and thermophilic digestion of sewage sludge, Water Res., $38,1653-1662$. 
Sötemann, S. W., Ristow, N. E., Wentzel, M. C., Ekama, G. A. (2005), A steady state model for anaerobic digestion of sewage sludges. Water SA, 31, 511-528.

Spajiš, R., Burns, R., Moody, L., Kralik, D. (2007), Anaerobic Digestion System Selection for Croatian Swine Manures, Proceedings of. $44^{\text {th }}$ Croatian \& $4^{\text {th }}$ International Symposium on Agriculture, 940-944.

Tabatabaei, M., Rahim, R. A., Wright, A. D. G, Shirai, Y., Abdullah, N., Sulaiman, A., Sakai, K., Hassan, M. A. (2010), Importance of the methanogenic archaea populations in anaerobic wastewater treatments, Process Biochemistry, 45, 1214-1225.
Tchobanoglous, G., Burton, F. L., Stensel, H. D. (2003). Waste-water Engineering: treatment and reuse. $\left(4^{\text {th }}\right.$ ed.). New Delhi: Tata McGraw-Hill.

The International Association for the Properties of Water and Steam (1997). Release on the IAPWS Industrial Formulation 1997 for the Thermodynamic Properties of Water and Steam. Erlangen, Germany.

Zeb, B. S., Mahmood, Q., Pervez, A. (2013), Characteristics and performance of anaerobic wastewater treatment (a review), J. Chem. Soc. Pak., 35, 217-232. 